\title{
BREVES CONSIDERAÇÕES SOBRE DESAFIOS E PERSPECTIVAS PARA A EFICIÊNCIA DO CUMPRIMENTO DE SENTENÇA E DO PROCESSO DE EXECUÇÃO NO BRASIL ${ }^{1}$
}

\author{
CONSIDERATIONS ABOUT THE CHALLENGES AND PERSPECTIVES OF THE
} FULFILLMENT AND THE ENFORCEMENT PROCEDURE IN BRAZIL

Aluisio Gonçalves de Castro Mendes Desembargador Federal do Tribunal Regional Federal da $2^{\text {a }}$ Região; Professor Titular de Direito Processual Civil na Faculdade de Direito da Universidade do Estado do Rio de Janeiro; Professor Titular de Direito Processual no Programa de Pós-Graduação em Direito da Universidade Estácio de Sá; Bolsista do Programa de Pesquisa e Produtividade da Universidade Estácio de Sá; Especialista em Direito Processual Civil pela Universidade de Brasília (UnB); Mestre em Direito pela Universidade Federal do Paraná (UFPR); Mestre em Direito pela Johann Wolfgang Universität (Frankfurt am Main, Alemanha); Doutor em Direito pela Universidade Federal do Paraná (UFPR), em doutorado cooperativo com a Johann Wolfgang Universität (Frankfurt am Main, Alemanha); Pós-Doutor em Direito pela Universidade de Regensburg (Alemanha); Diretor do Instituto Brasileiro de Direito Processual (IBDP); Diretor do Instituto Ibero-americano de Direito Processual; Membro da International Association of Procedural Law; Membro da Academia Brasileira de Letras Jurídicas (ABLJ). Rio de Janeiro/RJ. E-mail: aluisiomendes@terra.com.br

\footnotetext{
${ }^{1}$ Artigo recebido em 06/12/2021, sob dispensa de revisão.
} 
Larissa Clare Pochmann da Silva

Pós-Doutora em Direito Processual pela Universidade do Estado do Rio de Janeiro (UERJ). Doutora e Mestre em Direito pela Universidade Estácio de Sá (UNESA). Professora da Universidade Estácio de Sá (UNESA) e Coordenadora do Curso de Direito do Campus Recreio (RJ). Advogada. Rio de Janeiro/RJ. E-mail: larissacpsilva@gmail.com

RESUMO: O presente artigo trata dos atuais desafios para a eficiência do cumprimento e do processo de execução no Brasil, construindo possíveis propostas para sanar ou, pelo menos, reduzir os gargalos identificados para a execução no país.

PALAVRAS-CHAVE: Execução; desafios; perspectivas.

ABSTRACT: The article delas with the challenges for the efficiency of the fulfillment and the enforcement procedure in Brazil. In addition, some propositions will be made in an attempt to solve or, at least, reduce the gaps related to the enforcement in Brazil.

KEYWORDS. Enforcement; challenges; perspectives.

\section{INTRODUÇÃO}

O Conselho Nacional de Justiça $(\mathrm{CNJ})^{2}$ aponta, em seu relatório Justiça em Números, publicado no ano de 2020, a partir de dados coletados no ano de 2019, os principais entraves para o cumprimento dos julgados e para o processo de execução no Brasil. Embora ingressem no Poder Judiciário quase duas vezes mais casos na fase de

\footnotetext{
${ }^{2}$ CONSELHO NACIONAL DE JUSTIÇA (CNJ). Justiça em Números. Brasília: CNJ, 2020, p. 150. Disponível em: https://www.cnj.jus.br/wp-content/uploads/2020/08/WEB-V3-Justi\%C3\%A7a-emN\%C3\%BAmeros-2020-atualizado-em-25-08-2020.pdf. Acesso: 05/12/2021.
} 
conhecimento do que na de execução, no acervo a situação é inversa: a quantidade de execuções pendentes no Poder Judiciário é 54,5\% maior do que o número de processos de conhecimento. A maior parte dos processos de execução é composta pelas execuções fiscais, que representam $70 \%$ do estoque.

A partir desse cenário, passa-se, então, a retratar os desafios contemporâneos e possíveis perspectivas para a efetividade do cumprimento de títulos judiciais e do processo de execução no Brasil, que se referem aos entraves para atingir a finalidade de atendimento do interesse do credor, com o menor sacrifício do devedor ${ }^{3}$, como também envolvem fatores econômicos, culturais e de ordem prática.

\section{DESAFIOS DA EXECUÇÃO NO BRASIL}

As soluções consensuais ainda carecem, infelizmente, de adesão no âmbito dos conflitos existentes na sociedade brasileira ${ }^{4}$. O direito, até pouco tempo atrás, era vocacionado para o conflito, para a guerra. Hoje, as faculdades de direito possuem o papel de criar outra cultura, de fornecer profissionais abalizados para a solução, extrajudicial ou mesmo judicial, de modo consensual e, para isso, são necessárias pessoas que estejam devidamente conscientes e preparadas tecnicamente para realizar negociações, conciliações e mediações.

$\mathrm{Na}$ execução, ainda são escassas as tentativas de solução consensual. Segundo dados do Conselho Nacional de Justiça ${ }^{5}$, na série Justiça em Números, o percentual de acordos no processo de conhecimento foi de 17,2\% em 2015, 20,5\% em 2016, 20,1\% em 2017, 19,5\% em 2018 e 19,6\% em 2019. Esses números são reduzidos à terça parte quando se trata de soluções consensuais em execução: em 2015, o percentual foi de 3,5\%, em 2016 foi de 5\%, em 2017 foi de 6,2\%, em 2018 foi de 6\% e 6,1\% em 2019. Os credores

\footnotetext{
${ }^{3}$ ASSIS, Araken, Manual da Execução. 18.ed. São Paulo: RT, 2016, p. 141.

${ }^{4}$ As soluções consensuais são apontadas como uma das questões fundamentais à justiça contemporânea em MENDES, Aluisio Gonçalves de Castro. Desafios e perspectivas da justiça no mundo contemporâneo. Revista Eletrônica de Direito Processual, vol. 20, n. 3, set.-dez. 2019, p. 22.

${ }^{5}$ CONSELHO NACIONAL DE JUSTIÇA (CNJ). Justiça em Números. Brasília: CNJ, 2020, p. 172. Disponível em https://www.cnj.jus.br/wp-content/uploads/2020/08/WEB-V3-Justi\%C3\%A7a-emN\%C3\%BAmeros-2020-atualizado-em-25-08-2020.pdf. Acesso em 5 dez. 2021.
} 
insistem em buscar a percepção do crédito no Poder Judiciário, não estando tão dispostos à negociação quando, muitas vezes, o executado não tem patrimônio ou não tem patrimônio suficiente. Há de se destacar, no entanto, que há casos em que o Judiciário esgotou os meios previstos em lei e ainda assim não houve localização de patrimônio capaz de satisfazer o crédito, permanecendo o processo pendente. A negociação da dívida, com eventual pagamento parcelado dos valores devidos, pode ser uma forma de satisfação do crédito mais rápida e mais eficaz do que o tempo despendido com medidas judiciais na localização de bens do executado.

Ainda outro fator é que o espírito empresarial e a sociedade de consumo estimulam o endividamento das pessoas e o inadimplemento das obrigações pelo devedor deixou de ser vexatório e reprovável. Não se trata aqui do superendividamento do consumidor, regulado pela Lei $\mathrm{n}^{\circ} 14.181$, de $1^{\circ}$ de julho de 2021 , mas sim daqueles que celebram negócios jurídicos, contraem dívidas e acabam por não as honrar até o vencimento. Consequentemente, as cobranças estão se multiplicando e, como forma de tutela dos interesses do credor, o Poder Judiciário começa a repensar posições anteriores, não mais exigindo, por vezes, o exaurimento de medidas na busca da efetividade da execução. Um dos casos é, por exemplo, o INFOJUD. No âmbito do Tribunal Regional Federal da Segunda Região, foi fixada a seguinte tese em Incidente de Resolução de Demandas Repetitivas (IRDR): “A partir da Lei no 13.382/2006, para utilização do Sistema de Informações ao Judiciário (INFOJUD) é desnecessária a comprovação do prévio exaurimento das vias extrajudiciais na busca de bens a serem penhorados, não obstante a invocação do sigilo fiscal". (TRF2. Processo nº 0100171-06.2019.4.02.0000. Rel. Des. Federal Luiz Paulo da Silva Araújo Filho. Órgão Especial. DJ: 07/11/2019). No mesmo sentido, o Superior Tribunal de Justiça (STJ) tem consignado que: o "STJ firmou entendimento pela possibilidade da realização de pesquisas nos sistemas BACENJUD, RENAJUD E INFOJUD, anteriormente ao esgotamento das buscas por bens do executado, porquanto tais sistemas são meios colocados à disposição da parte exequente para agilizar a satisfação de seus créditos" (STJ. REsp 1941559 / RS. Rel. Min. Assusete Magalhães. Segunda Turma. DJ: 22/06/2021). 
Na tutela executiva, deve-se manter o equilíbrio entre a proteção dos direitos do executado, assegurando-lhe as garantias fundamentais, com a adoção de medidas efetivas para a realização do direito do credor.

Não obstante os desafios apontados, há medidas concretas quem pode contribuir para a efetividade da execução, caso venham atreladas à mudança cultural.

\section{PERSPECTIVAS}

Apresentam-se, agora, algumas perspectivas para a eficiência do cumprimento de sentença e do processo de execução no Brasil.

\section{a) Cadastro Nacional de Bens (CNB)}

Um dos percalços dos exequentes é a localização de bens penhoráveis do executado. A existência de um cadastro, a nível nacional, à disposição do Poder Judiciário, integrado com as serventias extrajudiciais, poderia permitir o acesso a bens imóveis, veículos e móveis, sujeitos a registro, em nome do executado, bem como a integração com cadastros já existentes. Essa consulta, a requerimento do autor ou do interessado, poderia tornar a execução mais efetiva ao trazer maior publicidade, com uma menor quantidade de atos, tanto em relação à existência de bens em nome do executado como em relação ao valor do patrimônio em seu nome, esclarecendo até mesmo sua situação patrimonial para satisfação do crédito do exequente.

Destaca-se que o que hoje vigora é: i) um Cadastro Nacional de Indisponibilidade de Bens (CNIB), interligado ao Conselho Nacional de Justiça (CNJ), que integra todas as indisponibilidades de bens decretadas por magistrados e por autoridades administrativas, mas não trata dos bens que poderiam ser passíveis de penhora; ii) o SISBAJUD, um sistema que interliga a Justiça ao Banco Central e às instituições financeiras, para agilizar a solicitação de informações e o envio de ordens judiciais ao Sistema Financeiro Nacional, via internet. 
O desenvolvimento de um sistema que interligasse as informações referentes ao registro de bens móveis e imóveis pode permitir uma redução na duração da quantidade de processos e da quantidade de atos processuais praticados na busca de bens do devedor. A ideia seria a construção de sistemas que poderiam ser acessados e utilizados, de modo isolado ou concentrado, permitindo-se um levantamento o mais amplo possível dos bens do devedor, de modo que o credor e o Poder Judiciário tivessem mecanismos mais efetivos na localização e penhora dos bens existentes.

\section{b) Reunião de processos contra o mesmo devedor}

A reunião de processos em face do mesmo devedor possui previsão no artigo 28 da Lei $n^{\circ}$ 6.830/1980 (Lei de Execução Fiscal - LEF), que estabelece que, para a garantia da execução, os processos poderão ser reunidos por dependência no juízo que recebeu a distribuição da primeira execução.

Conforme já decidiu a Primeira Seção do Superior Tribunal de Justiça (STJ) no julgamento do Recurso Especial no 1.158.766-RJ, de Relatoria do Ministro Luiz Fux, apreciado no dia 8 de setembro de 2010, a referida reunião de processos é uma faculdade do juiz, tendo como condição a conveniência da unidade da garantia, vale dizer, que haja penhoras sobre o mesmo bem efetuadas em execuções contra o mesmo devedor.

O precedente acima possui grande relevância porque aponta a possibilidade da reunião por determinação do magistrado. Isso deve ocorrer, independentemente de requerimento, pois, em certas situações, o credor que figura em determinada execução limita o seu interesse à obtenção do respectivo crédito. Desse modo, as preferências, materiais e processuais, seriam deixadas de lado, ou até mesmo burladas, deixando-se prevalecer interesses egoísticos e isolados de um ou alguns credores, em detrimento dos demais e do direito objetivo. Sendo assim, embora a norma contida na Lei de Execuções Fiscais seja um importante antecedente normativo, o seu comando central, ou seja, a possibilidade da reunião de execuções, não deve ficar condicionada somente ao requerimento do credor, podendo ser determinada de ofício pelo órgão judicial.

A dispersão de processos pode contribuir para a demora ou falta de efetividade nas execuções, na medida em que o demandado poderá indicar o mesmo bem ou um 
conjunto de bens em diversas execuções. Desse modo, cria a falsa aparência de garantia, propiciando-lhe, até mesmo, a dilapidação, total ou parcial, do resto do patrimônio não penhorado.

A reunião de processos contra o mesmo devedor em um único juízo poderá ser relevante para a satisfação dos credores, observando-se que os bens utilizados como garantia nas execuções sejam suficientes para a tutela do interesse dos credores.

Inclusive, no âmbito da Justiça do Trabalho, foi editado o Provimento CGJT n ${ }^{\circ}$, de 09 de fevereiro de 2018, do Tribunal Superior do Trabalho (TST), que dispõe sobre a reunião de execuções em face do mesmo devedor, buscando nítido propósito conciliatório, a eficiência, a quantificação do valor total da dívida e a análise da garantia, até mesmo para que o executado ofereça balanço patrimonial, no caso de pessoa jurídica, e possa se aferir se é devedor solvente.

Destaca-se que, no âmbito do Código de Processo Civil, o artigo 69, inciso II, trata da reunião ou apensamento de processos, prevendo a possibilidade de os órgãos do Poder Judiciário estabelecerem ato de cooperação para a "reunião ou apensamento de processos". Concorrendo diversas ações, seja no mesmo juízo, seja em diversos órgãos executantes, em cada um deles o oficial de justiça poderia efetuar a penhora sobre o mesmo bem do devedor, vinculando-o a diversos processos.

Esta previsão já poderia servir como iniciativa basilar justamente para a reunião das execuções em face do mesmo devedor, estendendo-se a iniciativa regulamentada pelo Tribunal Superior do Trabalho aos demais ramos do Poder Judiciário, de forma a proporcionar maior eficiência à execução civil.

\section{c) Fortalecimento e reiteração das medidas executivas}

$\mathrm{Na}$ execução, o autor pretende a satisfação mediante a realização de atos materiais concretos que sejam capazes e suficientes de transformar o dever ser em realidade ${ }^{6}$. $\mathrm{O}$ desfecho esperado da execução é a satisfação da obrigação prevista no título executivo.

\footnotetext{
${ }^{6}$ MENDES, Aluisio Gonçalves de Castro. Teoria Geral do Processo. Rio de Janeiro: Lumen Juris, 2009, p. 76-77.
} 
Para isso, são importantes o fortalecimento e a reiteração das medidas executivas coercitivas e sub-rogatórias até a satisfação do crédito ou a extinção anômala da execução. Tratando-se de penhora online, através do sistema do BACENJUD, o "Superior Tribunal de Justiça já se manifestou acerca da possibilidade de reiteração do pedido de penhora eletrônica, via sistema Bacenjud, desde que observado o princípio da razoabilidade" (STJ. AgInt no AREsp 1494995 / DF. Rel. Min. Moura Ribeiro. Terceira Turma. DJ: 30/09/2019) e, inclusive, no mesmo sentido o primeiro autor deste trabalho reiteradamente já decidiu enquanto Desembargador Federal no âmbito do Tribunal Regional Federal da Segunda Região ${ }^{7}$.

Destaca-se, inclusive, que, em dezembro de 2019, foi firmado Acordo de Cooperação Técnica entre o Conselho Nacional de Justiça - CNJ, o Banco Central e a Procuradoria da Fazenda Nacional - PGFN, visando o desenvolvimento de novo sistema para substituir o BacenJud e aprimorar a forma de o Poder Judiciário transmitir suas ordens às instituições financeiras, sendo que o novo sistema permite a reiteração automática de ordens de bloqueio (conhecida como "teimosinha").

A partir da emissão da ordem de penhora on-line de valores, o magistrado poderá registrar a quantidade de vezes que a mesma ordem terá que ser reiterada no SISBAJUD até o bloqueio do valor necessário para o seu total cumprimento ${ }^{8}$.

Da mesma forma, ao tratar do protesto do título executivo judicial, previsto no artigo 517, prevê, em seu parágrafo quarto, que o cancelamento do protesto ocorrerá, mediante ofício do juiz, no prazo de 3 (três) dias, contado da data de protocolo do requerimento, desde que comprovada a satisfação integral da obrigação.

Como no protesto, o fortalecimento das medidas executivas poderá, eventualmente, se dar com ações reiteradas ou que tiverem sua eficácia até a extinção da execução.

\section{d) Descentralização da execução}

\footnotetext{
${ }^{7}$ A título de exemplo, reporta-se aos julgamentos proferidos nos processos registrados sob o $\mathrm{n}^{\mathrm{o}} 0108109$ 28.2014.4.02.0000 e sob o $\mathrm{n}^{\mathrm{o}}$ 0214667-42.2017.4.02.5101.

${ }^{8}$ As informações estão disponíveis no endereço eletrônico do Conselho Nacional de Justiça (CNJ) em https://www.cnj.jus.br/sistemas/sisbajud/. Acesso em 5 dez. 2021.
} 
O modelo brasileiro de execução tem sua origem na tradição romano-germânica, com excessiva centralização dos atos executivos nas mãos do juiz. Porém, a atividade prática a ser desenvolvida na execução pouco ou nada tem em comum com o julgamento de litígios com fundamento em conhecimentos jurídicos. Inclusive, países como a Itália, a Alemanha e a França ${ }^{9}$ preveem a figura de um auxiliar do juízo, como executor. Nesses países, a execução é processada principalmente por servidores do Poder Judiciário, através dos agentes de execução. Após a provocação por parte do credor, a execução se inicia, respectivamente, com atos do ufficiale giudiziario, Gerichtsvollzieher e huissier, intervindo o juiz após consumada a penhora ao patrimônio do executado ou na ocorrência de algum incidente.

$\mathrm{Na}$ Alemanha, por exemplo, a execução inicia-se, através de provocação do exequente, com ato do executor oficial, que é funcionário da justiça. Ele tem o dever de analisar a presença dos requisitos necessários para a execução e realizar medidas executivas, mas caberá ao juízo analisar: i) qualquer objeção formulada sobre sua capacidade ou competência; ii) reclamação apresentada contra o procedimento executivo; iii) questionamento sobre custas.

Nota-se, portanto, que se descentraliza a atividade prática executiva, mas os atos decisórios continuam sob a supervisão ou controle do juiz competente.

No Brasil, como observa Leonardo Greco ${ }^{10}$ :

Hoje o juiz se transformou num burocrata, com a chamada penhora online. Pobre juiz! Há meses um juiz federal me disse que perdia um dia de trabalho por semana apertando o mouse do computador na efetivação da penhora on-line. Ouvi há dias no Espírito Santo que lá alguns juízes gastam mais de um dia por semana. O juiz é um funcionário caro, que percebe um dos mais altos salários do Estado. Nós estamos empregando toda a massa cinzenta desse juiz para ficar apertando com o dedo o mouse do computador. Parece que houve até um juiz que foi ao Supremo, arguindo a inconstitucionalidade da prática da penhora online pelo juiz, revoltado por ter sido reduzido a ser um oficial de justiça. Essa distorção é comumente justificada no sigilo e na segurança do sistema bancário, mas por que não aparelhar a justiça de funcionários

\footnotetext{
${ }^{9}$ Uma comparação entre os modelos dos países europeus sobre a descentralização da execução pode ser encontrada em: RIBEIRO, Flávia Pereira. Desjudicialização da execução civil. São Paulo: Saraiva, 2013, p. 83-154.

${ }^{10}$ GRECO, Leonardo. Op. Cit., p. 406.
} 
qualificados e responsáveis para efetuar a penhora online? Por que tem de ser o próprio juiz, com a sua senha pessoal? O juiz hoje é um escravo da burocracia da execução, esse mesmo juiz que vive angustiado com os processos que ele tem de instruir ou em que tem de dar sentenças, vigiado pelo $\mathrm{CNJ}$ com as suas metas irracionais, e ainda absorvido em parcela relevante do seu tempo numa tarefa puramente mecânica.

A descentralização da execução brasileira, a exemplo do que já ocorre com países da Europa, apesar de depender de autorização legislativa, permitiria que auxiliares da justiça pudessem, por delegação, realizar atos executivos, mantendo com o juiz os atos cognitivos mais relevantes, como a apreciação da impugnação dos atos realizados por seus auxiliares. Consequentemente, os magistrados estariam concentrados no ato de decidir, deixando seus auxiliares direcionados para a realização e eficácia dos atos executivos.

\section{e) Medidas atípicas}

O artigo 139, inciso IV, do Código de Processo Civil ${ }^{11}$ procurou superar a antiga tipicidade dos meios executivos, conferindo ao magistrado um poder geral de efetivação de suas decisões, em prol da obtenção da atividade satisfativa em tempo razoável, tal como preceituado pelo artigo $4^{\circ}$ do diploma. Nesse sentido, a apreensão de carteira nacional de habilitação e/ou suspensão do direito de dirigir, a apreensão de passaporte, a proibição de participação em concurso público e a proibição de participação em licitação pública são exemplos de medidas que vêm sendo aplicadas pelo Poder Judiciário, dentro de um debate sobre o seu cabimento e pressupostos.

O primeiro autor deste texto, inclusive, já deu provimento a um agravo de instrumento para deferir a apreensão de passaporte em um caso concreto ${ }^{12}$, justamente porque a possibilidade de concessão de medidas atípicas não significa a ausência de parâmetros ${ }^{13}$. O deferimento de medidas atípicas pressupõe o preenchimento de

\footnotetext{
${ }^{11}$ Em relação à constitucionalidade das medidas coercitivas, indutivas ou sub-rogatórias previstas no dispositivo, encontra-se pendente de apreciação a Ação Direta de Inconstitucionalidade (ADIn) n ${ }^{\circ}$ 5941/DF perante o Supremo Tribunal Federal.

${ }^{12} \mathrm{O}$ julgamento em questão foi proferido no bojo dos autos registrados sob o $\mathrm{n}^{\mathrm{o}}$ 500171596.2020.4.02.0000, no Tribunal Regional Federal da Segunda Região (TRF2).

${ }_{13}$ THEODORO JÚNIOR, Humberto. Curso de Direito Processual Civil. Vol. III. Rio de Janeiro: Gen/Forense, 53.ed., 2019, p. 218.
} 
requisitos, que tenham ou venham a ser abalizados pelos Tribunais Superiores e que se mostrem, nos casos concretos, razoáveis.

Um desses requisitos pode ser a subsidiariedade, especialmente quando mais gravosas: as medidas atípicas podem ser um soldado de reserva para as medidas típicas, conforme decidido no bojo do RHC 97.876/SP, de Relatoria do Ministro Luis Felipe Salomão, pela Quarta Turma do Superior Tribunal de Justiça em 5 de junho de 2018.

Outro requisito diz respeito aos corolários do contraditório e da fundamentação previstos no Código de Processo Civil de 2015, conforme consagrado no Recurso Especial $\mathrm{n}^{\circ}$ 1896421 / SP. Para que seja adotada qualquer medida executiva atípica deve o juiz intimar previamente o executado para pagar o débito ou apresentar bens destinados a saldá-lo, seguindo-se os atos de expropriação típicos. A decisão que autorizar a utilização de medidas coercitivas indiretas deve, ademais, ser devidamente fundamentada, a partir das circunstâncias específicas do caso, não sendo suficiente para tanto a mera indicação ou reprodução do texto do art. 139, IV, do CPC/15 ou mesmo a invocação de conceitos jurídicos indeterminados sem ser explicitado o motivo concreto de sua incidência na espécie.

A medida atípica deferida deve, ainda, ser proporcional e razoável, podendo contribuir para a satisfação da obrigação no caso concreto, conforme decidido no RHC 99.606/SP, de Relatoria da Ministra Nancy Andrighi, na Terceira Turma, julgado em 13 de novembro de 2018.

Nesse sentido, foi sintetizado pelo Superior Tribunal de Justiça que: “A adoção de meios executivos atípicos é cabível desde que, verificando-se a existência de indícios de que o devedor possua patrimônio expropriável, tais medidas sejam adotadas de modo subsidiário, por meio de decisão que contenha fundamentação adequada às especificidades da hipótese concreta, com observância do contraditório substancial e do postulado da proporcionalidade". (STJ. Recurso Especial n 1.788.950 - MT. Rel. Min. Nancy Andrighi. Terceira Turma. DJ: 23/04/2019)

O deferimento de medidas atípicas, a partir da análise desses parâmetros no caso concreto, é mais uma medida de apoio para a efetividade das decisões judiciais.

\section{CONCLUSÃO}


Os atuais desafios do processo de execução e do cumprimento de sentença no Brasil envolvem não apenas aspectos jurídicos, como questões econômicas, culturais e de ordem prática.

As ideias trazidas neste texto são apenas reflexões propostas para contribuir para a maior eficiência do cumprimento de sentença e do processo de execução no país. Essas medidas precisam vir, também, de uma mudança cultural, mas, naturalmente, desenvolvem-se algumas perspectivas com viabilidade de serem implementadas, que muito poderiam contribuir para a satisfação do direito do exequente, com o respeito às garantias fundamentais do executado.

\section{REFERÊNCIAS:}

ASSIS, Araken. Execução Forçada e Efetividade do Processo. Revista Sintese de Direito Processual Civil. Porto Alegre: IOB, vol., n.1, set.-out. 1999, p. 7-16.

. Manual da Execução. 18.ed. São Paulo: RT, 2016.

BARBOSA MOREIRA, José Carlos. O novo Processo Civil Brasileiro. Rio de Janeiro: Gen/Forense, 2012.

CARNEIRO, Paulo Cezar Pinheiro. O novo Processo Civil Brasileiro. Exposição sistemática do processo: de conhecimento; nos tribunais; de execução; da tutela provisória. Rio de Janeiro: Gen/Forense, 2019.

CONSELHO NACIONAL DE JUSTIÇA (CNJ). Justiça em Números. Brasília: CNJ, 2020. Disponível em: https://www.cnj.jus.br/wp-content/uploads/2020/08/WEBV3-Justi\%C3\%A7a-em-N\%C3\%BAmeros-2020-atualizado-em-25-08-2020.pdf. Acesso em 05/12/2021.

GRECO, Leonardo. Execução civil - entraves e propostas. Revista Eletrônica de Direito Processual, vol. 12, 2013, p. 399-445.

MENDES, Aluisio Gonçalves de Castro. Desafios e perspectivas da justiça no mundo contemporâneo. Revista Eletrônica de Direito Processual, vol. 20, n. 3, set.-dez. 2019, p. 20-32. . Teoria Geral do Processo. Rio de Janeiro: Lumen Juris, 2009. 
Revista Eletrônica de Direito Processual - REDP.

Rio de Janeiro. Ano 16. Volume 23. Número 1. Janeiro a Abril de 2022

Periódico Quadrimestral da Pós-Graduação Stricto Sensu em Direito Processual da UERJ

Patrono: José Carlos Barbosa Moreira (in mem.). ISSN 1982-7636. pp. 55-67

www.redp.uerj.br

RIBEIRO, Flávia Pereira. Desjudicialização da execução civil. São Paulo: Saraiva, 2013, p. 83-154.

THEODORO JÚNIOR, Humberto. Curso de Direito Processual Civil. Vol. III. Rio de Janeiro: Gen/Forense, 53.ed., 2019. 